\title{
A STUDY ON NEONATAL HEARING LOSS USING TRANSIENT EVOKED OTOACOUSTIC EMISSIONS
}

\author{
Jayaprabha Sathyabhama ${ }^{1}$, Arathi Karat ${ }^{2}$ \\ ${ }^{1}$ Additional Professor, Department of ENT, Government Medical College, Thiruvananthapuram. \\ ${ }^{2}$ Senior Resident, Department of ENT, Government Medical College, Thiruvananthapuram.
}

\begin{abstract}
Deafness is an invisible disability that may often go undetected until school age, especially in children with no additional disabilities. It affects the social, emotional and cognitive development of an individual. However, this can be overcome through early identification and intervention, for which a screening programme is mandatory. But choosing any option needs realistic assessment of the magnitude of the problem in terms of prevalence as well as the risk factors operating in that specific context. So this study was performed to plan future neonatal screening programmes at Medical College Hospital, Thiruvananthapuram. The study was conducted on 402 babies born at SAT Hospital, Medical College, Thiruvananthapuram. The prevalence of neonatal hearing loss was found to be $0.8 \%$. Craniofacial anomalies, family history of permanent childhood hearing loss and congenital infections were found to be the significant risk factors for hearing loss.
\end{abstract}

\section{KEYWORDS}

Neonatal Hearing Loss, Transient Evoked Otoacoustic Emissions (TEOAEs), BERA (Brainstem Evoked Response Audiometry), Risk Factors.

HOW TO CITE THIS ARTICLE: Sathyabhama J, Karat A. A study on neonatal hearing loss using transient evoked otoacoustic emissions. J. Evolution Med. Dent. Sci. 2016;5(17):871-875, DOI: 10.14260/jemds/2016/201

\section{INTRODUCTION}

Hearing loss is one of the most common congenital defects. Approximately one child in 1000 is born with a bilateral permanent childhood hearing impairment.[1] When children are identified with hearing loss at birth and receive intervention before 6 months of age, they catch up with their normal hearing peers and develop essentially normal language by 5 years of age.[2] Conversely, children who are identified with hearing loss later in life and receive intervention after 6 months of age, especially those with severe to profound hearing loss and with multiple handicaps struggle to catch up with their normal hearing peers. Yoshinaga Itano $\mathrm{C}$, et al.[3] in his study on "Developmental outcomes of children with hearing loss born in Colorado Hospital with and without universal hearing screening program" found that $84 \%$ of children born in screening hospitals were identified with hearing loss prior to six months of age as compared to $8 \%$ of children in non-screen group.

The screening strategies of young infants, specifically universal screening versus selective screening (High risk targeted approach) is a debate, especially in resource limited settings. In a study carried out by Huang LH, et al.[4] in China on Cost Effectiveness of Neonatal Hearing Screening Programme in China, they concluded that universal screening might be considered as the prioritized implementation goal, especially in those relatively developed provinces of China as it provides the best health and economic effects, while targeted screening might be temporarily more realistic than universal screening in those relatively developing provinces of China.

Financial or Other, Competing Interest: None.

Submission 07-01-2016, Peer Review 09-02-2016,

Acceptance 15-02-2016, Published 29-02-2016.

Corresponding Author:

Jayaprabha Sathyabhama,

Department of ENT,

Government Medical College,

Thiruvananthapuram-695011.

E-mail:jpsvinayak@gmail.com

DOI: $10.14260 /$ jemds/2016/201
The fact that selective screening may miss considerable number of cases is the justification for universal screening in less developed countries also. ${ }^{[5]}$ However, choosing any option needs realistic assessment of the magnitude of the problem in terms of prevalence of specific type of hard of hearing as well as the risk factors operating in that specific context. In this regard, the present study, a cross-sectional study was carried out to study the prevalence of neonatal hearing loss and study the association of various risk factors with the hearing loss.

\section{MATERIALS AND METHODS}

The study was conducted at Sree Avittam Thirunal (SAT Hospital) and Medical College Hospital (Government Medical College, Thiruvananthapuram).

\section{Study Design \\ Cross-Sectional Study.}

\section{Study Population}

Sample size: Calculated using the formula-

$$
\frac{N=Z \alpha^{2} P(1-P)}{d^{2}}
$$

Where,

$\mathrm{Z}$ is a constant, $\mathrm{Z}=1.96$ for $\alpha=0.05$ level

$\mathrm{P}$ is the prevalence of neonatal hearing loss, $\mathrm{P}=0.56 \%{ }^{[6]}$ $\mathrm{d}$ is precision, which is $20 \%$ of $\mathrm{P}$.

The sample size obtained with this calculation is 16,455 . As it is not feasible to study these many subjects in our setup, a random sample of all the babies born in two of the six units of Department of Obstetrics and Gynaecology were decided to be studied; 402 babies born between June 2013 and May 2014 in SAT Hospital in two (Unit 4 and Unit 6) out of the six units under the Department of Obstetrics and Gynaecology (Selected by simple random sampling) were included in the study. Babies whose parents did not give consent for testing were excluded from the study. 


\section{METHOD}

After obtaining an informed consent from the parents, a detailed history was taken and clinical examination carried out. A three stage hearing testing protocol was followed with TEOAE testing for stage 1 and 2 and BERA for stage 3. Babies were screened once with TEOAE testing in the neonatal period, 24 hours after delivery and prior to discharge in a sound proof room at SAT Hospital (by the second author). Babies who failed the test in either or both ears were subjected to a repeat test, at followup at around 6 weeks. Babies who failed this rescreening were subjected to BERA test within 3 months of age. The second and third stage testing was carried out by an audiologist in a sound proof room in the Audiology Department.

\section{Statistical Analysis}

The statistical analysis of the data collected was done with SAS 9.2, SPSS 15.0, Stata 10.1, MedCalc 9.0.1, Systat 12.0 and R environment ver. 2.11.1.

Descriptive and inferential statistical analysis was carried out. Results on continuous measurements are presented on Mean \pm SD (Min-Max) and results on categorical measurements are presented in number (\%). Significance was assessed at 5\% level of significance; 95\% Confidence Interval has been computed to find the significant features. Confidence Interval with lower limit more than $50 \%$ is associated with statistical significance. Chi-square test was used to find the significance of study parameters on categorical scale between two or more groups.

\section{RESULTS AND OBSERVATIONS}

A total of 402 babies were enrolled in the study. There were 208 female and 194 male babies; 118 babies failed ('Refer') the test in the right ear and 122 babies failed ('Refer') the test in the left ear in the initial screening (Fig. 1).

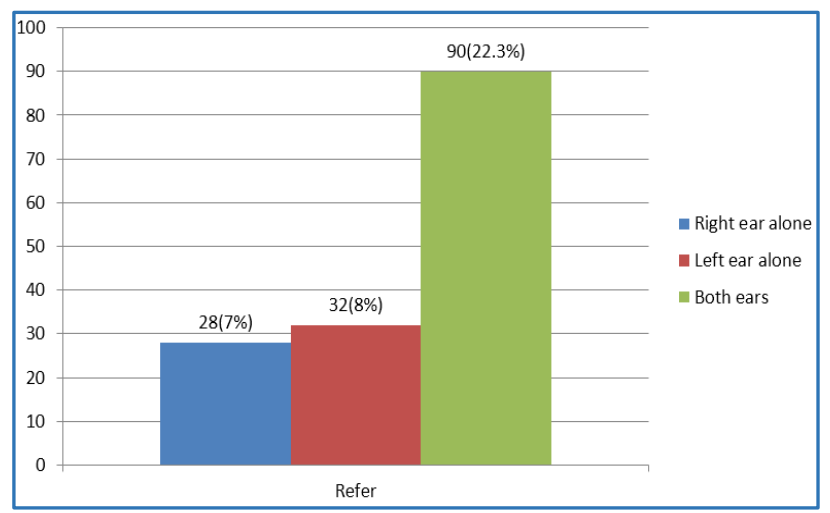

Fig. 1: First Screening Failures

Out of the 118 babies who failed the test in the right ear, 4 were lost to followup. In the remaining 114 babies, 109 passed and 5 babies failed ('Refer') the test (Fig. 2).

Out of the 122 babies who failed the test in the left ear, 7 were lost to followup. Among the remaining 115, 110 passed the test and 5 failed ('Refer') (Fig. 3).

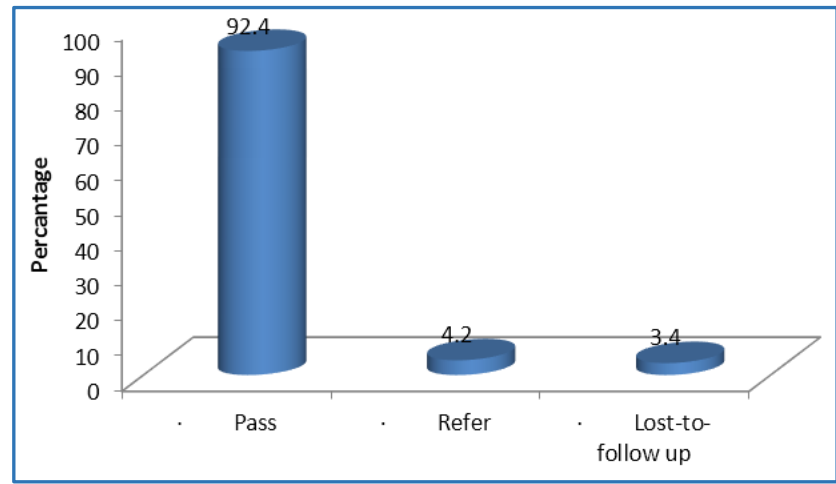

Fig. 2: TEOAE Retest Findings in Right Ear

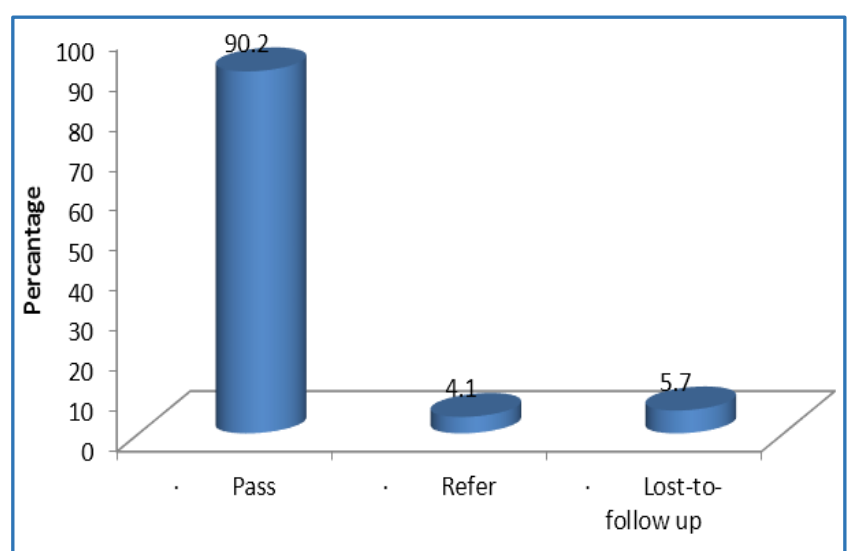

Fig. 3: TEOAE Retest Findings in Left Ear

Five babies were subjected to BERA. Among them, 3 babies were diagnosed to have hearing loss (Fig. 4). All the babies with hearing loss were female babies.

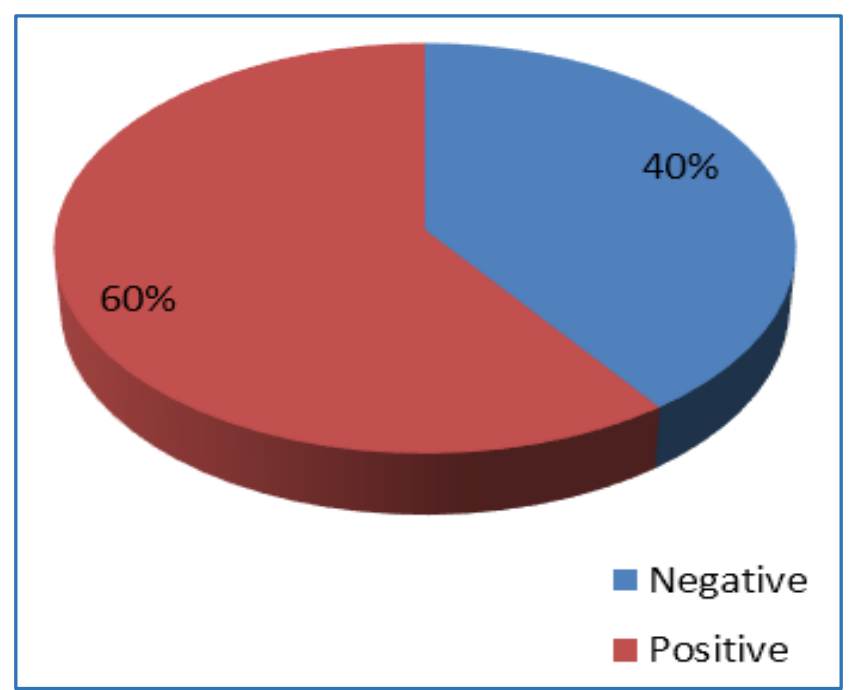

Fig. 4: BERA Findings

Prevalence of hearing loss was found to be $0.8 \%$ (Fig. 5). 


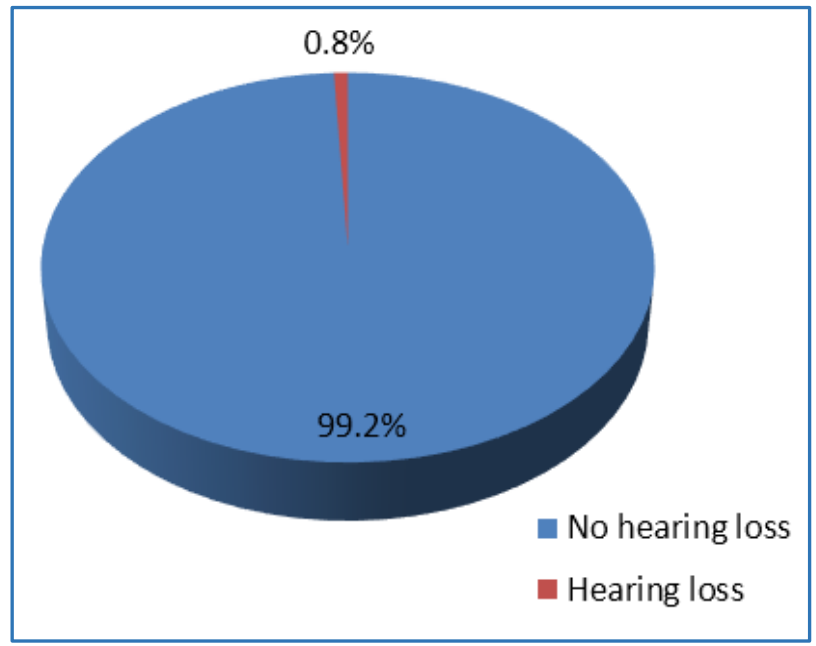

Fig. 5: Prevalence of Hearing Loss

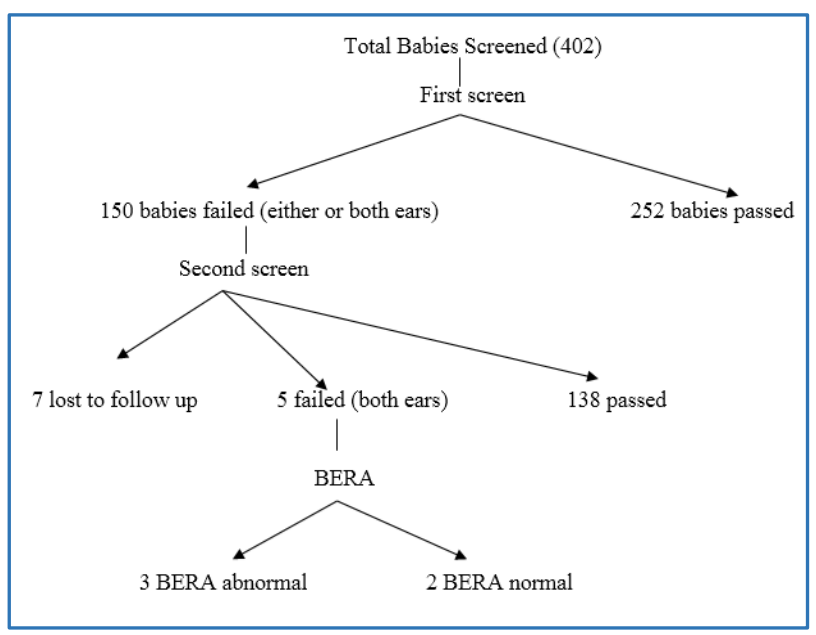

Fig. 6: Algorithm of Babies Screened for Hearing loss

1) Association with family history of hearing loss Out of the 402 babies studied, 5 babies had a family history of hearing loss; 1 among the 5 babies with a family history of hearing loss was detected to be hearing impaired. The association was found to be statistically significant.

\begin{tabular}{|c|c|c|c|}
\hline \multirow{2}{*}{$\begin{array}{c}\text { Family } \\
\text { History }\end{array}$} & $\begin{array}{c}\text { No Hearing } \\
\text { Loss }\end{array}$ & $\begin{array}{c}\text { Hearing } \\
\text { Loss }\end{array}$ & \multirow{2}{*}{ Total } \\
\hline No & $388(99 \%)$ & $2(66.7 \%)$ & $390(98.7 \%)$ \\
\hline Yes & $4(1 \%)$ & $1(33.3 \%)$ & $5(1.3 \%)$ \\
\hline Total & $392(100 \%)$ & $3(100 \%)$ & $395(100 \%)$ \\
\hline \multicolumn{3}{|c|}{ Table 1: Association of Hearing Loss with Family } \\
History of Hearing Loss \\
\hline
\end{tabular}

$\mathrm{P}<0.001$, Significant

\section{2) Association with craniofacial anomalies}

Among the babies studied, 8 babies had craniofacial anomalies; 2 babies among them were diagnosed to have hearing loss. The association was found to be statistically significant.

\begin{tabular}{|c|c|c|c|}
\hline \multirow{2}{*}{$\begin{array}{c}\text { Craniofacial } \\
\text { Anomaly }\end{array}$} & $\begin{array}{c}\text { Hearing Loss } \\
\text { Hearing } \\
\text { Loss }\end{array}$ & $\begin{array}{c}\text { Hearing } \\
\text { Loss }\end{array}$ & \\
\hline No & $386(98.5 \%)$ & $1(33.3 \%)$ & $387(98 \%)$ \\
\hline Yes & $6(1.5 \%)$ & $2(66.7 \%)$ & $8(2 \%)$ \\
\hline Total & $392(100 \%)$ & $3(100 \%)$ & $395(100 \%)$ \\
\hline Table 2: Association of Hearing Loss with Craniofacial \\
Anomalies \\
\hline
\end{tabular}

$\mathrm{P}<0.001$, Significant

3) Association with birth weight less than $1.5 \mathrm{~kg}$

There were 36 babies with birth weight less than $1.5 \mathrm{~kg}$. None of them were detected to have hearing loss. The association was not found to be statistically significant.

\begin{tabular}{|c|c|c|c|}
\hline \multirow{2}{*}{$\begin{array}{c}\text { Birth } \\
\text { Weight } \\
\text { (kg) }\end{array}$} & $\begin{array}{c}\text { Ho Hearing } \\
\text { Loss }\end{array}$ & $\begin{array}{c}\text { Hearing } \\
\text { Loss }\end{array}$ & \multirow{2}{*}{ Total } \\
\cline { 2 - 3 }$\geq 1.5$ & $356(90.8 \%)$ & $3(100 \%)$ & $359(90.9 \%)$ \\
\hline$<1.5$ & $36(9.2 \%)$ & $0(0 \%)$ & $36(9.1 \%)$ \\
\hline Total & 392(100\%) & $\mathbf{3 ( 1 0 0 \% )}$ & 395(100\%) \\
\hline \multicolumn{3}{|c|}{ Table 3: Association of Hearing Loss with } \\
Birth Weight Less Than 1.5 kg \\
\hline
\end{tabular}

$\mathrm{P}=0.582$, Not Significant

\section{4) Association with ototoxic medication}

153 out of the 402 babies had received ototoxic medication. One among them had hearing loss. The association was not statistically significant.

\begin{tabular}{|c|c|c|c|}
\hline \multirow{2}{*}{$\begin{array}{c}\text { Administration } \\
\text { of Ototoxic } \\
\text { Medication }\end{array}$} & $\begin{array}{c}\text { No Hearing } \\
\text { Loss }\end{array}$ & $\begin{array}{c}\text { Hearing } \\
\text { Loss }\end{array}$ & \multirow{2}{*}{ Total } \\
\cline { 2 - 3 } & $241(61.5 \%)$ & $2(66.7 \%)$ & $243(61.5 \%)$ \\
\hline No & $151(38.5 \%)$ & $1(33.3 \%)$ & $152(38.5 \%)$ \\
\hline Yes & $392(100 \%)$ & $3(100 \%)$ & $395(100 \%)$ \\
\hline Total & \multicolumn{3}{|c|}{ Table 4: Association of Hearing Loss with } \\
\hline \multicolumn{3}{|c|}{ Administration of Ototoxic Medication } \\
\hline
\end{tabular}

$\mathrm{P}=0.854$, Not Significant

5) Association with NICU stay for more than $\mathbf{5}$ days 46 of the 402 babies studied were admitted in the NICU for more than 5 days. One among them was detected to have hearing loss. The association was not found to be statistically significant.

\begin{tabular}{|c|c|c|c|}
\hline \multirow{2}{*}{$\begin{array}{c}\text { NICU } \\
\text { Stay }\end{array}$} & $\begin{array}{c}\text { No Hearing } \\
\text { Loss }\end{array}$ & $\begin{array}{c}\text { Hearing } \\
\text { Loss }\end{array}$ & \multirow{2}{*}{ Total } \\
\hline No & $347(88.5 \%)$ & $2(66.7 \%)$ & $349(88.4 \%)$ \\
\hline Yes & $45(11.5 \%)$ & $1(33.3 \%)$ & $46(11.6 \%)$ \\
\hline Total & $392(100 \%)$ & $3(100 \%)$ & $395(100 \%)$ \\
\hline \multicolumn{3}{|c|}{ Table 5: Association of Hearing Loss with NICU } \\
Stay for more than 5 Days \\
\hline
\end{tabular}

$\mathrm{P}=0.240$, Not Significant

6) Association with APGAR scores

15 of the 402 babies had an APGAR score between 0 to 4 at 1 minute and 0 to 6 at 5 minutes. None of these babies had hearing loss. The association was not found to be statistically significant. 


\begin{tabular}{|c|c|c|c|c|}
\hline \multirow{2}{*}{$\begin{array}{c}\text { APGAR } \\
\text { Score }\end{array}$} & $\begin{array}{c}\text { No Hearing } \\
\text { Loss } \\
\text { (n=392) }\end{array}$ & $\begin{array}{c}\text { Hearing } \\
\text { Loss } \\
(\mathbf{n}=3)\end{array}$ & $\begin{array}{c}\text { Total } \\
\mathbf{( n = 3 9 5 )}\end{array}$ & $\begin{array}{c}\text { P } \\
\text { value }\end{array}$ \\
\hline 1 min. & & & & \\
\hline$>4$ & $377(96.2 \%)$ & $3(100 \%)$ & $380(96.2 \%)$ & \multirow{2}{*}{0.730} \\
\hline 0 to 4 & $15(3.8 \%)$ & $0(0 \%)$ & $15(3.8 \%)$ & \\
\hline 5 mins. & & & & \\
\hline$>6$ & $387(98.7 \%)$ & $3(100 \%)$ & $390(98.7 \%)$ & \multirow{2}{*}{0.844} \\
\hline 0 to 6 & $5(1.3 \%)$ & $0(0 \%)$ & $5(1.3 \%)$ & \\
\hline \multicolumn{5}{|c|}{ Table 6: Association of Hearing Loss with APGAR Scores } \\
\hline
\end{tabular}

7) Association with maternal diabetes mellitus

63 of the 402 babies studied were born to diabetic mothers. None of them had hearing loss. The association was not found to be statistically significant.

\begin{tabular}{|c|c|c|c|}
\hline Maternal & \multicolumn{2}{|c|}{ Hearing Loss } & \multirow{2}{*}{ Total } \\
\cline { 2 - 3 } \begin{tabular}{c} 
Mellitus \\
\cline { 2 - 3 }
\end{tabular} & $\begin{array}{c}\text { No Hearing } \\
\text { Loss }\end{array}$ & $\begin{array}{c}\text { Hearing } \\
\text { Loss }\end{array}$ & \\
\hline No & $329(83.9 \%)$ & $3(100.0 \%)$ & $332(84.1 \%)$ \\
\hline Yes & $63(16.1 \%)$ & 0 & $63(15.9 \%)$ \\
\hline Total & $392(100.0 \%)$ & $3(100.0 \%)$ & $395(100.0 \%)$ \\
\hline \multicolumn{3}{|c|}{ Table 7: Association of Hearing Loss with } \\
Maternal Diabetes Mellitus \\
\hline
\end{tabular}

$P$ value $=0.45$, Not Significant

\section{DISCUSSION}

The prevalence of hearing loss in this study is $0.8 \%$. The relatively high value in our study could be because SAT Hospital is a tertiary referral centre and has a greater proportion of high risk newborns.

In the present series, out of the 402 babies studied 5 babies had a family history of hearing loss, that is $1.2 \%$ had a family history of hearing loss; 1 baby was born to deaf mute parents, mother and maternal uncle had hearing loss in another, 2 babies had a history of hearing loss in a maternal uncle and another a history of hearing loss in older sibling. The baby born to deaf mute parents was detected to have hearing loss. Association of family history of hearing loss with neonatal hearing loss was found to be significant ( $\mathrm{p}$ value $<0.001$ ) in our study. This is comparable to the findings of Nie $W$, et al.[7] In another study carried out by Imam S.S. et al.[5] in Egypt, consanguinity was the most prevalent risk factor for hearing loss comprising $46 \%$.

Eight out of the $402(2 \%)$ babies had a craniofacial anomaly. Three babies had preauricular skin tags and one each had low set ears, cryptotia, cleft palate, unilateral choanal atresia and retrognathia. The babies with cryptotia and retrognathia were detected to have hearing loss. The association of craniofacial anomalies with neonatal hearing loss was found to be statistically significant $(\mathrm{p}<0.001)$. Similar findings were found in studies by Nie W, et al.[7] Stilianos E. Kountakis, et al.[8] and Lachowska M, et al.[9]

36 out of the $402(9 \%)$ babies born had a birth weight of less than $1.5 \mathrm{~kg}$. None of these babies had hearing loss. The association with low birth weight was not found to be statistically significant $(p=0.582)$. This is against the findings of Nie W, et al.[7] Stilianos E. Kountakis, et al..8] Akinola.[10] and John Jewel, et al.[11] and could be due to the smaller sample size in the present study.
153 out of the 402 (38.1\%) babies were administered ototoxic medication. The medications administered included amikacin and vancomycin. Only one of the babies administered, these medications was found to have hearing loss. The association was not found to be statistically significant. However, in a study by Bielecki, et al.[12] in which 5282 infants were examined, only a small percentage $(2.86 \%)$ of SNHL appeared to be due to the use of ototoxic medications, despite the fact that this factor was the most prevalent (33.13\%) of all analysed risk factors of hearing impairment. After ototoxic medications, the frequencies of risk factors in their study were as follows: premature birth (16.21\%); low birth weight $(12.04 \%)$; intensive care in excess of 7 days $(10.64 \%)$. As the number of coexisting risk factors increases, the probability of SNHL in infants is also seen to increase. For children with one to four coexisting risk factors, the probability of SNHL ranges from $3.15 \%$ to $5.56 \%$; for five or more risk factors the probability nearly doubles. In our study, the baby with hearing loss who had been administered ototoxic medication, also had CMV infection, osteopetrosis and retrognathia and was admitted in the NICU for 6 days.

46 of the $402(11.4 \%)$ babies studied were admitted in the NICU for more than 5 days. One among them who was detected to have hearing loss, was admitted in NICU for 6 days. The association with NICU admission in the present study was not found to be statistically significant $(\mathrm{p}=0.24)$. However, in studies by Martínez-Cruz et al.[13] and Lachowska M et al.[9] longer stay in NICU and under mechanical ventilation was associated with a significant risk of hearing loss. It is possible that babies with auditory neuropathy could have been missed in our study as the initial screening was carried out with TEOAE testing only.

Fifteen of the $402(3.7 \%)$ babies had an APGAR score of 0 to 4 at 1 minute and $5(1.2 \%)$ babies had an APGAR score of 0 to 6 at 5 minutes. The $P$ values were 0.73 and 0.844 and were not statistically significant. However, in studies by Meyer $C$ et al.[14] and John Eichwald et al.[15] these APGAR scores were found to be statistically significant. The lack of association in this study is probably due to the smaller sample size.

Sixty three of the 402 (15.7\%) babies studied were born to diabetic mothers. Among them, 58 mothers had gestational diabetes mellitus and were on diet control; 4 mothers had gestational diabetes and were on insulin therapy. One mother had type 1 diabetes mellitus and was on insulin therapy from 7 years of age. None of the babies born to the diabetic mothers had hearing loss. There was no significant association of maternal diabetes mellitus with hearing loss in the present study ( $p$ value=0.45). However, in a study by Stilianos E. Kountakis, et al.[8] maternal diabetes mellitus was found to be significantly associated with neonatal hearing loss. Also, in a study by Akeem Olasisi et al.[16] maternal preeclampsia was found to be a significant risk factor for hearing loss. Maternal diabetes mellitus and preeclampsia are not included as risk factors for hearing loss in the JCIH 2007 guidelines.[17] Further studies will be needed to determine whether inclusion of these additional risk factors in a hearing screening program will be necessary.

\section{CONCLUSION}

In our study, the prevalence of neonatal hearing loss is $0.8 \%$. Family history of hearing loss, craniofacial anomalies and intrauterine infection were found to be the significant risk 
factors. Very low birth weight, administration of ototoxic medication, APGAR score 0 to 4 at 1 minute and 0 to 6 at 5 minutes, NICU admission for more than 5 days and maternal diabetes mellitus were not found to have a significant association with neonatal hearing loss.

Universal Newborn Hearing Screening (UNHS) has become a national practice in most developed countries. The identification of all newborns with hearing loss before 6 months of age has now become a realistic and attainable goal. Although hearing impairment has an adverse effect on language acquisition, communication and cognitive development, these can be overcome through early detection and intervention. In this pilot study carried out, screening was carried out randomly. We could identify hearing loss in 'at risk' babies only. This is probably due to our limited sample size. Further study will be needed to determine whether inclusion of additional risk factors in a hearing screening program can provide an efficacious alternative to the use of UNHS. The full potential of the technological advances that have been made in diagnostic audiology and rehabilitation and treatment of the hearing impaired can only be rightfully exploited if early identification of hearing impaired babies is meticulously carried out.

\section{ACKNOWLEDGEMENTS}

We thank the Audiologists of the Audiology Department, Ms Chippi Mohan, Ms Pralima L., Ms Geethi S. and Ms Lavanya M. without whom the present study would not have been possible.

\section{REFERENCES}

1. Sujata De, Sue Archbold, Ray Clarke. Investigation and management of the deaf child. Scott-Brown's Otorhinolaryngology, Head and Neck Surgery. Great Britain:Edward Arnold Ltd, 2008; $7^{\text {th }}$ ed:p 844.

2. Yoshinaga-Itano C. Early intervention after universal neonatal hearing screening: impact on outcomes. Ment Retard Dev Disabil Res Rev 2003;9(4):252-66.

3. Yoshinaga-Itano C, Coulter D, Thomson V. Developmental outcomes of children with hearing loss born in colorado hospitals with and without universal newborn hearing screening programs. Semin Neonatol 2001;6(6):521-9.

4. Huang LH, Zhang L, Tobe RYG, et al. Cost-effectiveness analysis of neonatal hearing screening program in china: should universal screening be prioritized? BMC Health Serv Res 2012;12(1):97.
5. Imam SS, El-Farrash RA, Taha HM, et al. Targeted versus universal neonatal hearing screening in a single Egyptian center. ISRN Pediatr 2013;2013:574937.

6. Nagapoornima P, Ramesh A, Srilakshmi, et al. Universal hearing screening. Indian J Pediatr 2007;74(6):545-9.

7. Nie W, Wu H, Qi Y, et al. A case-control study on high-risk factors for newborn hearing loss in seven cities of shandong province. J Huazhong Univ Sci Technolog Med Sci 2007;27(2):217-20.

8. Stilianos E Kountakis, Ioannis Skoulas, Diane Phillips, et al. Risk factors for hearing loss in neonates: a prospective study. Am J Otolaryngol 2002;23(3):133-7.

9. Lachowska M, Surowiec P, Morawski K, et al. Second stage of neonatal hearing screening-a way for diagnosis and beginning of proper treatment for infants with hearing loss. Adv Med Sci 2014;59(1):90-4.

10. Akinola MD, Onakoya PA, Tongo 0 , et al. Neonatal hearing screening using transient evoked otoacoustic emission in a sub-urban population in Nigeria. Int J Otolaryngol Head Neck Surg 2014;3(4):205-11.

11. John Jewel, Varghese PV, Tejinder Singh, et al. Newborn hearing screening-experience at a tertiary hospital in northwest India. Int J Otolaryngol Head Neck Surg 2013;2(5):211-4.

12. Bielecki I, Horbulewicz A, Wolan T. Risk factors associated with hearing loss in infants: an analysis of 5282 referred neonates. Int J Pediatr Otorhinolaryngol 2011;75(7):925-30.

13. Martínez-Cruz, Poblano A, Fernandez Carrocera LA. Risk factors associated with sensorineural hearing loss in infants at the neonatal intensive care unit: 15-year experience at the national institute of perinatology (Mexico City). Arch Med Res 2008;39(7):686-94.

14. Meyer C, Witle J, Hildmann A, et al. Neonatal screening for hearing disorders in infants at risk: incidence, risk factors, and follow-up. Pediatrics 1999;104(4):900-04.

15. John Eichwald, Thomas Mahoney. Apgar scores in the identification of sensorineural hearing loss. J Am Acad Audiol 1993;4(3):133-8.

16. Akeem O Lasisi, Paul A Onakoya, Taye J Lasisi, et al. Neonatal hearing screening in a rural/sub-urban ommunity in Nigeria, sub-saharan Africa- a preliminary report. Intl J Otorhinolaryngol 2014;78(9):1452-5.

17. Joint Committee on Infant Hearing. Year 2007 position statement: principles and guidelines for early hearing detection and intervention programs. Pediatrics 2007;120(4):898-921. 